\title{
Effects of 6-Week Micronutrient Supplementation on Sperm Parameters and Pregnancy Outcomes in Males with Idiopathic Infertility Undergoing Fertility Interventions: A Pilot Cohort Study
}

\author{
Choo Gim Sun ${ }^{1 *}$, Aw Lin $\mathrm{Da}^{2}$, Ooi Bee Sen², Zamri Yusof ${ }^{2}$, Huan-Keat Chan ${ }^{3}$, Kathirgamanathan \\ Balanathan ${ }^{4}$, Murizah Mohd Zain² \\ ${ }^{1}$ Obstetrics and Gynaecology Department, Penang General Hospital, Jalan Residensi, 10990, Pulau Pinang, \\ MALAYSIA. \\ ${ }^{2}$ Reproductive Unit, Obstetrics and Gynaecology Department, Sultanah Bahiyah Hospital, Alor Setar, Kedah, \\ MALAYSIA. \\ ${ }^{3}$ Clinical Research Centre, Sultanah Bahiyah Hospital, Alor Setar, Kedah, MALAYSIA. \\ ${ }^{4}$ Department of Obstetrics and Gynaecology, Seberang Jaya Hospital, Penang, MALAYSIA.
}

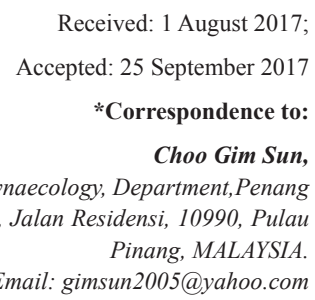

Email: gimsun2005@yahoo.com

Copyright: (C) the author(s),publisher and licensee Indian Academy of Pharmacists. This is an openaccess article distributed under the terms of the Creative Commons Attribution Non-Commercial License, which permits unrestricted non-commercial use, distribution, and reproduction in any medium, provided the original work is properly cited.

\begin{abstract}
Objective: To evaluate the effectiveness of the consumption of Profortil ${ }^{\circledR}$, a combination of eight micronutrients, on sperm count, sperm motility, and pregnancy outcomes following a fertility intervention among infertile males in Malaysia. Methods: A cohort study was undertaken at the Seberang Jaya Hospital and the Sultanah Bahiyah Hospital, Malaysia. A total of 90 infertile males were enrolled, 52 of which decided to take two capsules of Profortil ${ }^{\circledR}$ daily for a six-week period during $1^{\text {st }}$ September and $30^{\text {th }}$ November 2016. Those who decided not to consume Profortil ${ }^{\circledR}$ served as the control group $(n=38)$. Semen analysis and an observation of pregnancy outcomes following the fertility interventions were conducted after 6 weeks. Results: Despite the consumption of Profortil ${ }^{\circledR}$, both groups showed a significant increase in sperm count $(p<0.001)$, but no change in sperm motility after 6 weeks. Although the difference in increment of sperm count between two groups was not significant, more participants who took Profortil ${ }^{\circledR}$ achieved a sperm count above 15 million/mL (25\% versus 18.4\%). The Proforti ${ }^{\circledR}$ group also demonstrated a higher pregnancy rate following the fertility interventions (26.9\% versus $18.4 \%)$. Conclusion: The findings suggest that Profortil ${ }^{\circledR}$ could be helpful in improving the sperm parameters and pregnancy outcomes. Nevertheless, to optimize its effectiveness, a longer supplementation duration is likely to be needed.

Key words: Micronutrient Supplementation, Sperm count, Oligospermia, Male infertility, Pregnancy outcome.
\end{abstract}

\section{INTRODUCTION}

Infertility is defined as the inability to conceive after one year of regular and unprotected intercourse among the same couple. ${ }^{[1]}$ It is a common global phenomenon, with approximately 10 to $17 \%$ of couples having either primary or secondary infertility problems. Of all these cases, at least 25 to $30 \%$ are contributed by male factors. ${ }^{[1]}$ Some of the conditions with a specific cause, such 
as hypogonadism, varicocele, genital tract infections and obstructions, gonadotropin-releasing hormone $(\mathrm{GnRH})$ deficiency, and sperm autoimmunity, are treatable. However, it is noteworthy that almost half of the male infertility cases, which are characterized by seminal abnormalities are idiopathic. ${ }^{[1,2]}$

As data concerning pathogenesis of defective sperm production in idiopathic male infertility is limited, there is generally a lack of effective treatment options. To date, there has been no evidence to support the use of androgen and gonadotropin for enhancing fertility in male population. ${ }^{[3]}$ Furthermore, there is insufficient evidence to support the use of anti-estrogen and aromatase inhibitor in treating this condition. ${ }^{[3]}$ Rather, one of the most commonly used strategy to achieve pregnancy in such cases is to increase sperm count and sperm motility, followed by using Assisted Reproductive Technology (ART), such as Intrauterine Insemination (IUI). Alternatively, In-vitro Fertilization (IVF) is reserved for severe male infertility cases, especially when patients fail to increase their sperm count and motility despite the efforts made, as its cost is much higher than those of other ARTs. ${ }^{[1,3]}$

Micronutrients, including vitamins, minerals, and trace elements, have been tested and advocated to enhance spermatogenesis and the quality of sperms. ${ }^{[4]}$ Recently, a systematic review also demonstrated the usefulness of antioxidant supplementation in infertile men, which ultimately resulted in improved live birth and pregnancy rate among the couples undergoing fertility interventions. ${ }^{[3]}$ In Malaysia, Profortil ${ }^{\circledR}$, a micronutrient supplement, has been widely used by infertile men to increase sperm count and motility prior to fertility interventions. Each capsule of Profortil ${ }^{\circledR}$ contains eight micronutrients that are known to be helpful in boosting sperm production and activity, including L-carnitine, L-arginine, zinc, vitamin $\mathrm{E}$, glutathione, selenium, coenzyme Q10 and folic acid. ${ }^{[5-11]}$ According to Imhof, a 3-month supplementation with Profortil ${ }^{\mathbb{R}}$ can lead to an increment of sperm count by $215.5 \%$, and of motility by $83.1 \%$ in sub fertile males. ${ }^{[12]}$

Nonetheless, in Malaysian public hospitals, Profortil ${ }^{\circledR}$, unlike other medications, is not provided to the patients free of charge. As patients need to bear the purchasing cost, it has always been taken for a shorter duration than that of recommended; for example, in the Seberang Jaya Hospital, Penang, and the Sultanah Bahiyah Hospital, Alor Setar, a 6-week supplementation with Profortil ${ }^{\circledR}$ preceding fertility interventions have been recommended to patients. Hence, this study was specifically designed to assess the effects of the 6-week supplementation of Porfortil ${ }^{\circledR}$ on sperm count, sperm motility, and pregnancy outcomes following the fertility interventions.

\section{METHOD}

Study Design and Setting: This is a pilot cohort study, undertaken during $1^{\text {st }}$ September and $31^{\text {st }}$ November 2016 at the Seberang Jaya Hospital, Penang, and the Sultanah Bahiyah Hospital, Alor Setar. These study sites selected are, respectively, public secondary and tertiary care centers, which are funded and operated by the Ministry of Health, Malaysia. The study protocol was registered with the National Medical Research Registry, Malaysia (NMRR-16-1805-32570), while the ethics approval was obtained from the Medical Research Ethics Committee, Malaysia.

Study Participants: Male patients with idiopathic infertility, who were under follow-up at one of the selected sites during the study period, were included in this study. The exclusion criteria were azoospermia, aspermia, clinical varicocele and having recent urogenital infection. All eligible patients were recommended to take Profortil ${ }^{\circledR}$, which they needed to purchase from the community pharmacy, for six weeks prior to the fertility intervention. The participants who decided not to take Profortil ${ }^{\circledR}$ served as the control group in this study; however, similar with those taking Profortil ${ }^{\circledR}$, they also received obstetrician-based counselling on lifestyle modification to improve sperm production and quality. Eventually, the decision on which fertility intervention (either IUI or IVF) to use for each patient was made by the obstetricians, with the sperm count and motility after six weeks, partner's condition, and individual preference taken into consideration. The selection of fertility intervention was also subject to the financial ability of participants, as it was only partially subsidized by the government.

Data collection and Assessment: Prior to any data collection procedures, all participants were briefed on the study information, and were subsequently required to provide informed consent. Their baseline characteristics, including age, ethnicity, and the type of infertility (primary or secondary), were recorded upon the recruitment. Thereafter, a specimen of seminal fluid was collected from each participant for laboratory analysis, during which the sperm count (in million/ $\mathrm{mL}$ ) and motility (in \%) were recorded and used as 
the baseline for comparisons. Throughout the 6-week period, adherence of the patients who took Profortil ${ }^{\circledR}$ was monitored though phone calls. The semen analysis was repeated after six weeks, while pregnancies were assessed by serum beta-human chorionic gonadotropin hormone taken from the participants' partners after 15 days following the fertility interventions, whereby the serum level higher than $25 \mathrm{IU}$ were acknowledged as a pregnancy. ${ }^{[13]}$ The differences in sperm count and motility following the consumption of Profortil ${ }^{\circledR}$ served as the primary endpoint in this study. Besides, the proportions of patients in both groups who had sperm count and motility higher than the lower limits recommended by the WHO were reported. ${ }^{[14]}$ Furthermore, the pregnancy rates of both groups were presented as the secondary endpoint.

Statistical Analysis: Statistical analysis was performed using the SPSS ${ }^{\circledR} 20.0$ software (IBM, New York). All categorical data were presented as frequencies and percentages, whereas numerical data were presented as means and standard deviations (SD). The differences between two groups in baseline characteristics were identified using Pearson's chi-square and independent- $t$ tests, as appropriate. Moreover, the differences between two groups in sperm count and motility were assessed using independent- $t$ tests, whereas the within-group differences were assessed using paired-t tests. A p-value $<0.05$ was considered as statistically significant.

\section{RESULTS}

During the study period, a total of 90 infertile men attending the fertility clinic were enrolled. Fifty-two $(57.8 \%)$ of them decided to take Profortil ${ }^{\circledR}$, while the remaining 32 patients who decided not to take Profortil ${ }^{\circledR}$ served as the control group. Two groups did not differ in baseline characteristics, including the type of infertility Table 1. Both groups demonstrated a significant increase in sperm count $(p<0.001)$, but no change in sperm motility after 6 weeks Table 2. Although the difference in increment of sperm count between two groups was insignificant, a higher proportion of participants who took Profortil ${ }^{\circledR}$ achieved a sperm count above 15 million/ $\mathrm{mL}$ in comparison with the control group (25\% versus $18.4 \%$ ) Table 3 . A total of 29 $(55.8 \%)$ and $30(78.9 \%)$ patients from the Profortil ${ }^{\circledR}$ and control groups were, respectively, arranged for IUI, while the rest underwent IVF. The pregnancy rate of the Profortil ${ }^{\circledR}$

\begin{tabular}{|c|c|c|c|}
\hline Characteristics & $\begin{array}{l}\text { Profortil® } \\
\text { group }(n=52)\end{array}$ & $\begin{array}{l}\text { Control } \\
\text { group }(n=38)\end{array}$ & $P$ value \\
\hline $\begin{array}{l}\text { Age, years, } \\
\text { mean SD) }\end{array}$ & $34.25(4.74)$ & $32.24(5.09)$ & $0.057^{a}$ \\
\hline \multicolumn{4}{|l|}{ Ethnicity, n (\%) } \\
\hline Malay & $26(50)$ & $23(60.5)$ & $0.465^{b}$ \\
\hline Chinese & $9(17.3)$ & $7(18.4)$ & \\
\hline Indian & $17(32.7)$ & $8(17.8)$ & \\
\hline \multicolumn{4}{|c|}{ Infertility type, n (\%) } \\
\hline Primary & $45(86.5)$ & $28(73.7)$ & $0.124^{b}$ \\
\hline Secondary & $7(13.5)$ & $10(26.3)$ & \\
\hline
\end{tabular}

\begin{tabular}{|c|c|c|c|c|c|c|}
\hline & \multicolumn{3}{|c|}{ Sperm count Mean (SD), million/mL } & \multicolumn{3}{|c|}{ Sperm Motility Mean (SD), \% } \\
\hline & $\begin{array}{l}\text { Profortil }{ }^{\circledR} \\
\text { group }(n=52)\end{array}$ & $\begin{array}{l}\text { Control } \\
\text { group }(n=38)\end{array}$ & $\begin{array}{l}p \\
\text { value }^{a}\end{array}$ & $\begin{array}{l}\text { Profortil® } \\
\text { group }(n=52)\end{array}$ & $\begin{array}{l}\text { Control } \\
\text { group }(n=38)\end{array}$ & $\begin{array}{l}p \\
\text { value }\end{array}$ \\
\hline Pre-treatment & $6.90(4.50)$ & $7.74(3.18)$ & 0.299 & $35.56(24.47)$ & $39.74(15.45)$ & 0.325 \\
\hline Post-treatment & $10.94(9.27)$ & $10.71(5.80)$ & 0.882 & $42.44(24.08)$ & $41.47(14.78)$ & 0.814 \\
\hline$p$-value ${ }^{b}$ & $<0.001$ & $<0.001$ & - & 0.053 & 0.446 & - \\
\hline Mean percentage of change from baseline & $+58.0 \%$ & $+38.0 \%$ & - & $+6.8 \%$ & $+1.73 \%$ & - \\
\hline
\end{tabular}




\begin{tabular}{|c|c|c|c|c|}
\hline & \multicolumn{2}{|c|}{ Sperm count $>15$ million $/ m L \quad n(\%)$} & \multirow{2}{*}{$\begin{array}{l}\text { Sperm Motility }>40 \% \\
\text { Profortil® group } \\
(n=52)\end{array}$} & \multirow{2}{*}{$\begin{array}{l}n(\%) \\
\text { Control group }(n=38)\end{array}$} \\
\hline & $\begin{array}{l}\text { Profortil@ group } \\
(n=52)\end{array}$ & Control group $(n=38)$ & & \\
\hline Pre-treatment & $1(1.9)$ & $0(0)$ & $21(40.4)$ & $24(63.2)$ \\
\hline Post-treatment & $13(25.0)$ & $7(18.4)$ & $30(57.7)$ & $23(60.5)$ \\
\hline Percentage of increment & $23.1 \%$ & $18.4 \%$ & $17.3 \%$ & $-2.6 \%$ \\
\hline
\end{tabular}

group was $26.9 \%$, whereas only $18.4 \%$ of the participants in the control group were pregnant.

\section{DISCUSSION}

To our knowledge, this is the first study to evaluate the impacts of the 6-week micronutrient supplementation (Profortil $^{\circledR}$ ) on the sperm parameters among the males with idiopathic infertility. Additionally, it also adds to the existing literature by assessing the pregnancy outcomes among patients who underwent fertility interventions following the consumption of Profortil ${ }^{\circledR}$. While patients in Malaysia have been receiving Profortil ${ }^{\circledR}$ for a shorter period than that of recommended by the previous study, the findings show that the changes of sperm count and motility were not significant in comparison with the control group. However, there was a trend of more patients who received Profortil ${ }^{\circledR}$ achieving a sperm count and motility higher than the lower limits recommended by the WHO. ${ }^{[14]}$ Therefore, it is very possible that Profortil ${ }^{\circledR}$ can have a positive impact on the sperm parameters, but a longer period of supplementation is required to demonstrate the change.

The findings also demonstrate the importance of lifestyle modification, such as decrease in nicotine and alcohol consumption, and improvement in nutrition, as all participants achieve significant increment of sperm count despite the consumption of Profortil ${ }^{[} .^{[12]}$ Hence, it is imperative to ensure that all patients are properly educated and counselled by the obstetricians prior to the infertility interventions. Moreover, a higher pregnancy rate was shown in the Profortil ${ }^{\circledR}$ group. Nonetheless, it is noteworthy that the number of participants who underwent IVF interventions was two times higher than that of the control group. It is likely that the participants, who are did not take Profortil ${ }^{\circledR}$, were not able to financially afford IVF. This is because not only they needed to purchase the Profortil ${ }^{\circledR}$, the IVF surgical procedures, such as oocyte retrieval, embryo transfer and embryo freezing, were also required to be self-funded by the patients. Therefore, the influences of Profortil $^{\circledR}$ on the success of fertility interventions might not be fully reflected by this study.

This study is limited, as it is a non-randomized, observational study with a relatively small sample size. To have a true picture of the usefulness of micronutrient supplementation, future studies should also exclude underlying female factors and financial issues that could impact the selection of the fertility interventions.

\section{CONCLUSION}

Overall, this study shows that Profortil ${ }^{\circledR}$ could be helpful in improving the sperm parameters and pregnancy outcomes, as there was a trend of more patients who took Profortil ${ }^{\circledR}$ achieving a sperm count and motility higher than the lower limits recommended by the WHO, and a higher proportion of them were pregnant following either IUI or IVF. However, to optimize its effectiveness, a longer supplementation duration is likely to be needed.

\section{CONFLICT OF INTEREST}

No conflicts of interest.

\section{ACKNOWLEDGEMENT}

All authors have made substantial contributions in relation to the research design, statistical analysis and interpretation and drafting and approval of the final version of this manuscript. I would like to thank the Director of Health Malaysia for permission to publish this paper.

\section{FUNDING}

This is a self-sponsored study, and is not supported by any pharmaceutical company. 


\section{ABBREVIATIONS USED}

GnRH: Gonadotropin-releasing hormone, ART: Assisted Reproductive Technology, IUI: Intrauterine Insemination, IVF: In vitro Fertilization, WHO: World Health Organization.

\section{REFERENCES}

1. Templeton A. Infertility - Epidemiology, Aetiology and Effective Management. Health Bull (Edinb). 1995;523. (1995;53(5):294-8.)

2. Isidori AM. Medical treatment to improve sperm quality. Reproductive Biomed Online. 2006;12(6):704-14.

3. Agarwal A, Allamaneni SS. Sperm DNA Damage Assessment: A Test Whose Time Has Come. Fertility and Sterility. 2005;84(4):850-3.

4. Hertz M. "Considerations in Determining Sample Size for Pilot Studies Research in Nursing and Health Journal. 2008;31(2):180-91.

5. Scibona M, Meschini P, Capparelli S. L-arginine and male infertility, Minerva Urologica Nefrologica. 1994;46(4):251-3.

6. Suleiman SA, Ali ME, Zaki ZM, El-Malik EM, Nasr MA. Lipid peroxidation and human sperm motility: protective role of vitamin E. J Androl.1996;17(5):530-7.

7. Vezina D. Selenium-vitamin E supplementation in infertile men. Effects on semen parameters and micronutrient levels and distribution. Biological Trace Elem Res. 1996;53(1):65-83.

8. Ernster L, Dallner G. Biochemical, physiological and medical aspects of ubiquinone function. Biochimica Biophysica Acta. 1995;1271(1):195-204.

9. Kvist U, Kjellberg S, Bjorndahl L, Soufir JC, Arver S. Seminal fluid from men with agenesis of the Wolffian ducts: zinc-binding properties and effects on sperm chromatin stability. Inter J Andrology. 1990;13(4):245-52.

10. World Health Organisation. [Laboratory manual of the WHO for the examination of human semen and sperm-cervical mucus interaction]. Ann Ist Super Sanita. 2001;37(1):1-123.

11. Wong WY, Thomas CM, Merkus JM, Zielhuis GA, Steegers-Theunissen RP. Male factor subfertility: possible causes and the impact of nutritional factors. Fertility Sterility. 2000;73(3):435-42.

12. Imhof M, Lackner J, Lipovac M, Chedraui P, Riedl C. Micronutrient Supplement Increases Sperm Quality in The Sub-Fertile Male. European Med J Urology. 2014;1:60-65.

13. Bernstein HB, Van-Buren G. Chapter 6. Normal Pregnancy and Prenatal Care. In: DeCherney AH, Nathan L, Laufer N, Roman AS. Eds Current Diagnosis and Treatment: Obstetrics and Gynecology, 11e. New York, NY: McGraw-Hill. 2013.

14. Papillon-Smith J, Dahan MH. Pregnancy Rates with Insemination: Comparing the 1999 and 2010 World Health Organization Semen Analysis Parameters Norms. Obstetrics and Gynecology. 2015;125:60S.

Cite this article as: Choo GS, Aw LD, Ooi BS, Yusof Z, Chan HK, Balanathan K, Zain MM. Effects of 6-Week Micronutrient Supplementation on Sperm Parameters and Pregnancy Outcomes in Males with Idiopathic Infertility Undergoing Fertility Interventions: A Pilot Cohort Study. J Pharm Pract Community Med. 2017;3(4):220-4. 